\title{
Perceptions and practices regarding menstruation in adolescent girls in Yazd
}

\author{
Sedighah Akhavan Karbasi, Motahhareh Golestan, Razieh Fallah \\ Shaheed Sadoughi University of Medical Sciences, \\ Department of Pediatrics, Shaheed Sadoughi Hospital, Yazd, Iran, \\ Department of Pediatric Neurology, Shaheed Sadoughi Hospital, Yazd, Iran
}

\begin{abstract}
Objective: Puberty is the most prominent stage of life. The purpose of this study was to evaluate effects of puberty health education on promoting of its awareness in girls.

Methods: In an interventional quasi-experimental study (pre and post test), awareness, attitude and practice of 500 high school first grade student girls evaluated before and after health education in Yazd in 20042005.

Results: Mean age of menarche was 13.46 \pm 1.12 . Over ninty three percent (93.6\%) of girls had a previous information about menstruation where mother was the major source (53\%). Good and poor knowledge were seen in $36 \%$ and $28.6 \%$ respectively but practice was seen in $24.4 \%$ and $32.8 \%$ respectively. $85.2 \%$ of girls believed that menarche is evidence of health, but in $91.6 \%$ girl's menarche was associated with worry and shame. Negative psychological attitude about menstruation was seen in $59.8 \%$. The mean number of knowledge and practice before and after intervention was 5.3 $\pm 2.9,11.8 \pm 2.18$ and $4.3 \pm 1.8$ and $10.2 \pm$ 2.3 respectively ( $P V=0.0001)$.
\end{abstract}

Conclusion: Educational programs are needed for girls and their mothers to correct misinformation about exercise, food restrictions and good health puberty and menarche.

Key words: Awareness, education, knowledge, practice, puberty

\section{Introduction}

Adolescence is a period when physical growth and maturation are accompanied by mental and psychological development. ${ }^{1}$ Adolescence is a turbulent period in girls, which includes stressful events like menarche, considered as a landmark of female puberty. ${ }^{2}$

One might expect that menarche will be positively received by young women; however, negative responses such as shame, fear, anxiety and depression are more common. The manner in which a girl learns about menstruation and its associated changes may have an impact on her response to the event of menarche. Social practices about menstruation make girl child feel subnormal and may hamper her development. ${ }^{3}$ Menarche may remain a traumatic event for her, unless she is prepared for it. Most studies on female adolescence focus on the gynecological problems but problems of nutritional and psychological origin can not be ignored. ${ }^{2}$

The purpose of this study was to evaluate effects of puberty health education on promoting of it's awareness in girls.

Correspondence

Sedighah Akhavan Karbasi MD

Assistant Professor. Shaheed Sadoughi University of Medical Sciences,

Department of pediatrics, Shaheed Sadoughi Hospital, Yazd, Iran

Fax:00983518224100, Phone: 00983518224000 - 9, Mobile: 00989131519229

Email: sakarbasi@yahoo.com 


\section{Methods}

This was an interventional quasi-experimental (prepost) study, which was carried out in 2004-2005 for determining of knowledge, attitude and practice of girls about menarche.

Hence, present study was undertaken to assess the:

1) Source of information regarding menstruation

2) Reaction to first menstruation

3) Hygiene practiced during menstruation

4) Restrictions as result of menstruation and evaluation of the effect of education factor on awareness among girls in Yazd, central city in Iran.

Sample size with confidence interval of $95 \%$ determined 500 girls attained menarche whom selected in a systematic randomized method among high school first grade student girls. The data were collected after gaining permission from school authorities and were gotten by using questionnaires, including personal and public information (15 questions) and some questions related to menstruation practice, emotional reaction to menarche, source of information regarding menstruation, restrictions related to menstruation and hygiene practiced during menstruation. To evaluate knowledge, attitude and practice, 14 questions with one degree allocated to each one prepared. Degree 1$4,5-9$ and 10-14 was considered as bad, middle and good respectively and attitude of girls about psychological and behavioral manifestations of menarche determined as agree, disagree and indifferent. The questionnaire was first explained to school girls and then they were asked to fill it carefully, and the queries of the respondents were answered by principal research worker during the study.

Three month after education (face to face and pamphlet), the students were re-tested with first questionnaire. The data were analyzed using SPSS.13 statistical software. Mean numbers in awareness, attitude and practice were compared with pairedsamples t-test. Differences were considered significant at $\mathrm{P}$ values $<0.05$.

\section{Result}

Mean age of students and their menarche was $14.33 \pm 0.5$ years and $13.46 \pm 1$ years respectively. Sixty per cent of parents were illiterate or preliminary educated. There was previous information about menstruation in $93.6 \%$ and $74 \%$ of students achieved it before menarche. The sources of information were, mother $(53 \%)$, friends $(22.4 \%)$, health teacher (11.6), sister $(11.5 \%)$ and magazine $(1.2 \%)$. Good and poor knowledge were seen in $36 \%$ and $28.6 \%$ but practice was seen in $24.4 \%$ and $32.8 \%$ respectively.

Knowledge and practice ranking about puberty and menarche in shown in Table 1.

$42.6 \%$ of girls didn't know about first sign of puberty and only $19.2 \%$ of them answered correctly.

Exercise and diet restriction in menstrual period were seen in $50.6 \%$ and $58.6 \%$ respectively and $28.2 \%$ of girls didn't take bath, $21 \%$ didn't wash their external genitalia after defecation and $7 \%$ didn't use sanitary pad.

Although $85.2 \%$ of girls believed that menarche was hallmark of normal puberty and health, but in $91.6 \%$ of them, it was shame, fear and worry.

Negative and positive attitude about psychological change in puberty and menarche were seen in 59.8\% and $25.9 \%$ respectively. There was negative psychological feelings about menstruation in $78 \%$.

Dysmenorrhea occurred in 58\% students and in $18 \%$ it was severe with absence in school.

Mean number of knowledge and practice before and after intervention was $5.3 \pm 2.9$ and $11.8 \pm 2.18$ and $4.3 \pm$ 1.8 and 10.2 $\pm 2.3(\mathrm{PV}=0.0001)$.

\section{Discussion}

Adolescent girls constitute a vulnerable group and the manner in which a girl learns about menstruation and its associated changes may have an impact on her response to the event of menarche. ${ }^{3}$ In this study the mean age of menarche was $13.46 \pm 1$, but in Nigeria 13.6 years. ${ }^{4}$ In Turkey: $13.28 \pm 1.09$ and 12.9 years $^{5,6}$ and in Portugal $12.53 \pm 1.27$ years . ${ }^{7}$

In Yazd the awareness about menstruation was seen in 93.6\% of girls but in India this varies from $28 \%$ to $66.5 \%$. $2,8,9$ Sadhna reported that $14.4 \%$ of girls in high and upper middle and $18.4 \%$ in lower middle socioeconomic status have no knowledge about adolescent physical change and menarche. ${ }^{1}$

Table I. Knowledge and practice ranking about puberty and menarche in student

\begin{tabular}{llcc}
\hline Grade & Ranking & $\begin{array}{c}\text { Knowledge } \\
(\%)\end{array}$ & $\begin{array}{c}\text { Practice } \\
(\%)\end{array}$ \\
\hline $1-4$ & bad & 24.4 & 32.8 \\
$5-9$ & middle & 39.6 & 38.6 \\
$10-14$ & good & 36 & 28.6 \\
\hline
\end{tabular}


Our study emphasizes that major source of information about puberty and menstrual problems are mother, same as in Turkey, India and Sweden. ${ }^{1,6,10}$ In these studies although the major source of information about puberty and menstrual problems was mother, but she was often unable to meet the queries. This might be due to better relation among mother and daughter, but teachers in urban areas in India ${ }^{3}$ and cable and internet in Karachi ${ }^{11}$ were cited as major sources of information.

In present study, poor knowledge was seen in $28.6 \%$ but in Nigeria was $40 \%{ }^{12}$

In Yazd, in $91.6 \%$ of girls, menarche was associated with shame, fear and worry but these feelings in India and China were seen in $4485 \%$ and $85 \%, 3,13$ respectively. In Nigeria $84 \%$ of girls were not psychologically prepared for menarche. ${ }^{12}$

Majority of girls had negative reaction to menarche and this might be a reflection of taboos and prejudices about menstruation in society. Reaction to menstruation depends upon awareness and knowledge about the subject. ${ }^{3}$

In this study, $50 \%$ of girls had exercise restriction in menstrual periods and in India, physical activity restriction varies from $14.9 \%$ (10.6\% in urban and $20.3 \%$ in rural areas) to $50 \% .3,14$

In Yazd, restriction in diet was seen in $58 \%$ but in Nigeria only in $8 \% .^{15}$

In present study, $7 \%$ of girls didn't use sanitary pads while in Nigeria it was $66.3 \%,{ }^{12}$ but in India $98.5 \%$ of girls used clothes. ${ }^{14}$ That may be due to poverty and high cost of these pads.

In this study, $58 \%$ of girls had dysmenorrhea but this is $67 \%$ in $\mathrm{Nepal}^{16}$, Egypt $44.8 \%{ }^{17}$, Turkey $38.7 \%{ }^{6}$, and in Coimbra (Portugal) $51 \%{ }^{7}$

It is obvious that sources of information are not adequate and majority of girls have only partial or incomplete knowledge of facts on menarche and puberty and there is a need for further education.

In Yazd, negative and positive attitude towards psychological change in puberty and menarche were $59.8 \%$ and $25.9 \%$ respectively and negative psychological feels about menstruation (discomfort, guilt, impatient and obstinacy) were in 78\%. Attitudes prior to menarche affect the experience of menarche, menstruation and dysmenorrhea ${ }^{18}$. Those "totally unprepared", and especially early-developed girls, usually have more negative attitudes to menarche than others. ${ }^{19}$
Our study emphasizes that awareness and practice about menstruation and its health are not adequate and negative psychological feels about menstruation is due to lack of correct information. Major source of information for adolescent about puberty and menstrual problems is mother, but she is often unable to meet the queries, and majority of girls have only partial or incomplete knowledge of facts on menarche and puberty and educational programs needed for girls and their mothers to correct misinformation about puberty and menarche.

\section{Conclusion}

Educational programs is needed for girls and their mothers to correct misinformation about exercise, food restrictions, good health, puberty and menarche .

\section{References}

1. Sadhna G, Achala S. Awareness about reproduction and adolescent changes among school girls of different socioeconomic status. J Obstet Gynecol India 2006;56( 4): 324-328.

2. Bansal R D and Mehra M. Adolescent girls: An emerging priority. Indian Journal of public health 1998; 42 (1): 1.

3. Deo DS, Ghattargi CH .Perceptions and Practices Regarding Menstruation: A Comparative Study in Urban and Rural Adolescent Girls. Indian Journal of Community Medicine 2005; 30(1).

4. Jack TH,Obed JY, Agida ET, Petrova GV. Dysmenorrhoea and menstural abnormalities among postmenarcheal secondary school girls in Maiduguri in Nigeria. Afr J Med Sci 2005 ;34 (1):87-9.

5. Vicdan K , Kukner S, Dabakoglu T, Ergin T, Keles G,Gokmen O Demographic and epidemiologic features of female adolescents in Turkey.J Adolesc Health 1996;18(1):54-8.

6. Demir SC, Kadayyfey TO, Vardar MA, Atay Y. Dysfunctional uterine bleeding and other menstrual problems of secondary school students in Adana, Turkey, J Pediatr Adolesc Gynecol 2000;13(4):171-5.

7. Padez C, Rocha MA. Age at menarche in Coimbra (Portugal) school girls: a note on the secular chang. Ann Hum Biol 2003; 30(5):622-32.

8. Ahuja A, Tewari S. Awareness of pubertal changes among adolescent girls. J Fam Welfare 1995; 41:46-50.

9. Shiela, W, Malathy K, Premila, S. Menstrual and gynaecological disorders in 500 school girls in Madras city. J Obstet Gynaecol India 1993; 43:940-5. 
10. Gun I. Rembeck, Margareta Möller \& Ronny K. Gunnarsson.Attitudes and feelings towards menstruation and womanhood in girls at menarche Acta Paediatrica 2006;95(6) :707-714.

11. Ali TS, All PA, Waheed H, Memon AA. Understanding of puberty and related health problems among female adolescents in Karachi Pakistan. J Pak Med Asso 2006; 56(2):68-7223.

12. Abioye-Kuteyi EA . Menstrual knowledge and practices amongst secondary school girls in Ile Ife, Nigeria. J R Soc Health 2000; 120(1):23-6.

13. Tang CS, Yeung DY,Lee AM .Psychological correlates of emotional responses to menarche among chinese adolescent girls. J Adolesc health 2003; 33(3):193-201.

14. Darkshayani Devi K, Venkata Ramaiah P.A study on menstural hygiene among rural adolescent girls .Indian J med Sci 1994; 48(6):139-43.
15. Irinoye OO, Ogungbemi A, Ojo Ao. Menstruation: knowledge, attitude and practices of students in Ile-Ife, Nigeria. Niger J Med. 2003; 12(1):43-51.

16. Sharma M, Gupta S. Menstrual pattern and abnormalities in the high school girls of Dharan: A cross sectional study in tow boarding schools.Nepal Med coll J 2003;5(1):34-36.

17. El-Gilany AH, Banawi K, El-Fedawy S. Epidemiology of dysmenorrhea among adolescent students in Mansoura, Egypt. East Mediterr Health J 2005; 11(1-2):155-63.

18. Koff E Rierdan Premenarcheal expectations and postmenarcheal experiences of positive and negative menstrual related changes, J Adolesc Health 1996; 18: 286-91.

19. Ruble DN Brooks-Gunn J. The experience of menarche .Child Dev 1982; 53: 1557-66. 